\title{
Endomorphin-2 and Endomorphin-I Promote the Extracellular Amount of Accumbal Dopamine via Nonopioid and Mu-Opioid Receptors, Respectively
}

\author{
Hiroko Okutsu ${ }^{1,6}$, Shu Watanabe ${ }^{2}$, Ichiro Takahashi ${ }^{3}$, Yuri Aono², Tadashi Saigusa*,2,4, Noriaki Koshikawa ${ }^{2,4}$ \\ and Alexander R Cools ${ }^{5}$ \\ 'Department of Pharmacology, Faculty of Pharmaceutical Sciences, Tokyo University of Science, Noda-shi, Chiba, Japan; ${ }^{2}$ Department of \\ Pharmacology, Nihon University School of Dentistry, Chiyoda-ku, Tokyo, Japan; ${ }^{3}$ Department of Dental Anaesthesiology, Nihon University \\ School of Dentistry, Chiyoda-ku, Tokyo, Japan; ${ }^{4}$ Division of Oral and Craniomaxillofacial Research, Dental Research Centre, Nihon \\ University School of Dentistry, Chiyoda-ku, Tokyo, Japan; ${ }^{5}$ Department of Psychoneuropharmacology, University of Nijmegen, Nijmegen, \\ The Netherlands
}

\begin{abstract}
Activation of mu-opioid receptors in the nucleus accumbens (NAc) is known to increase accumbal dopamine efflux in rats. Endomorphin-2 (Tyr-Pro-Phe-Phe- $\mathrm{NH}_{2}$; EM-2) and endomorphin-I (Tyr-Pro-Trp-Phe-NH $\mathrm{NH}_{2}$ EM-I) are suggested to be the endogenous ligands for the mu-opioid receptor. As the ability of EM-2 and EM-I to alter the accumbal extracellular dopamine level has not yet been studied in freely moving rats, the present study was performed, using a microdialysis technique that allows on-line monitoring of the extracellular dopamine with a temporal resolution of $5 \mathrm{~min}$. A $25 \mathrm{~min}$ infusion of either EM-2 or EM-I into the NAc (5, 25, and 50 nmol) produced a dose-dependent increase of the accumbal dopamine level. The EM-2 (50 nmol)- and EM-I (25 and $50 \mathrm{nmol})$-induced dopamine efflux were abolished by intra-accumbal perfusion of tetrodotoxin $(2 \mu \mathrm{M})$. Intra-accumbal perfusion of the mu-opioid receptor antagonist CTOP (D-Phe-Cys-Tyr-D-Trp-Orn-Thr-Phe-Thr-NH $2 ; 3$ nmol) failed to affect the EM-2 (50 nmol)-induced dopamine release, whereas it significantly inhibited the EM-I (25 and $50 \mathrm{nmol}$ )-induced dopamine release. The EM-I ( $50 \mathrm{nmol})$-induced accumbal dopamine efflux was significantly reduced by the systemic administration of the putative mul-opioid receptor antagonist naloxonazine ( $15 \mathrm{mg} / \mathrm{kg}$, intraperitoneally (i.p.), given $24 \mathrm{~h}$ before starting the perfusion). Systemic administration of the aspecific opioid receptor antagonist naloxone ( $\mathrm{mg} / \mathrm{kg}$, i.p., given 10 or 20 min before starting the perfusion) also failed to affect the EM-2 (50 nmol)-induced dopamine efflux, whereas it significantly inhibited the EM-I (25 and $50 \mathrm{nmol}$ )-induced dopamine efflux. The present study shows that the intra-accumbal infusion of EM-2 and EM-I increases accumbal dopamine efflux by mechanisms that fully differ. It is concluded that the effects of EM-2 are not mediated via opioid receptors in contrast to the effects of EM-I that are mediated via mul-opioid receptors in the NAc.
\end{abstract}

Neuropsychopharmacology (2006) 31, 375-383. doi:I 0. I038/sj.npp. I 300804; published online 20 July 2005

Keywords: opioid; endomorphin-2; endomorphin-I; dopamine release; nucleus accumbens; rat

\section{INTRODUCTION}

Endomorphin-2 (Tyr-Pro-Phe-Phe- $\mathrm{NH}_{2} ; \mathrm{EM}-2$ ) and endomorphin-1 (Tyr-Pro-Trp-Phe- $\mathrm{NH}_{2}$; EM-1) are isolated from bovine (Zadina et al, 1997) as well as human brains

\footnotetext{
*Correspondence: Dr T Saigusa, Department of Pharmacology, Nihon University School of Dentistry, I-8-13, Kanda-Surugadai, Chiyoda-ku, Tokyo I0I-83I0, Japan, Tel: +8I 33219 8I26, Fax: +81 33219 8|36, E-mail: saigusa@dent.nihon-u.ac.jp

${ }^{6}$ Current address: Pharmacology Laboratories, Institute for Drug Discovery Research, Astellas Pharma Inc., Ibaraki, Japan

Received 18 January 2005; revised 25 April 2005; accepted 18 May 2005

Online publication: 25 May 2005 at http://www.acnp.org/citations/ Npp052505050038/default.pdf
}

(Hackler et al, 1997) and considered to be the endogenous ligands for the mu-opioid receptor (Goldberg et al, 1998; Zadina et al, 1997). The immunoreactivity of EM-2 and EM1 is prominently present in regions in which mu receptors are concentrated. Thus, large amounts of EM-2-like immunoreactivity (Schreff et al, 1998) and EM-1-like immunoreactivity (Martin-Schild et al, 1999) have been found in the nucleus accumbens (NAc) that contains various subtypes of opiate receptor (mu-, kappa- and delta-opioid receptors). Pharmacologically, the two endomorphins are potent analgesics and show similar properties (Goldberg et al, 1998). Both EM-2 and EM-1 produce short acting, naloxone-sensitive antinociception in the tail flick test (Stone et al, 1997). However, pharmacological intervention studies have also revealed that the mechanisms of 
the action of the two endomorphins are not completely identical. Thus, the antinociceptive effect of EM-2 is more sensitive to naloxonazine than that of EM-1 (Sakurada et al, 1999, 2000, 2001, 2002). The studies of Sakurada and coworkers have suggested that EM-2 acts predominantly as a mu1-opioid receptor agonist and EM-1 as a mu2-opioid receptor agonist.

The activation of mu-opioid receptors in the NAc induces a large and rapid increase of accumbal dopamine efflux. Thus, fentanyl, a mu receptor agonist, increases the naloxone-reversible accumbal dopamine efflux (Yoshida et al, 1999). The ability of the EM-2 and EM-1 to alter the extracellular amount of accumbal dopamine in freely moving rats has not yet been studied. Therefore, we analyzed the effects of EM-2 and EM-1 on the extracellular amount of dopamine in the NAc of freely moving rats, using the recently improved microdialysis technique that allows on-line monitoring of dopamine with a temporal resolution of $5 \mathrm{~min}$ instead of $20 \mathrm{~min}$ (Saigusa et al, 2001; cf. Fusa et al, 2002, 2005; Murai et al, 1994; Saigusa et al, 1997, 1999; Takada et al, 1993; Tomiyama et al, 1993, 1995).

First, we examined the effects of the sodium channel blocker tetrodotoxin (TTX) on the EM-2- and EM-1induced increase of extracellular dopamine in order to establish whether the effects are dependent on neural activity. Next, we analyzed whether mu-opioid receptors are involved in the effects of EM-2 and EM-1. For that purpose, CTOP (D-Phe-Cys-Tyr-D-Trp-Orn-Thr-Phe-Thr$\mathrm{NH}_{2}$ ), a mu-opioid receptor antagonist, together with EM2 or EM-1 was locally infused into the NAc. In order to investigate the putative involvement of mul-opioid receptors on the EM-1-induced accumbal dopamine efflux, the effects of the systemically administered mul-opioid receptor antagonist naloxonazine (Pasternak and Wood, 1986) were also studied. Given the finding that CTOP did not antagonize the effects of EM-2, it became necessary to establish the opioid nature of the effects of EM-2. For that purpose, an additional experiment on naloxone, an opioid receptor antagonist that acts at all opioid receptor subtypes, although with a greater affinity for mu-opioid receptors, was included. Naloxone was chosen, because studies on antinociceptive behavior (Stone et al, 1997; Goldberg et al, 1998), motor behavior (Mehta et al, 2001), electrophysiological studies (Chapman et al, 1997; Wang et al, 2000), and systemic blood pressure studies (Czapla et al, 1998; Champion et al, 1997) have revealed that EM-2 and EM-1 produce naloxone-sensitive effects. The pretreatment by naloxone was carried out $20 \mathrm{~min}$ before and $10 \mathrm{~min}$ before starting the intra-accumbal infusion of the EM-1 or EM-2. The 20 min paradigm was chosen, since it has been found to be effective in antagonizing the increase of accumbal dopamine efflux induced by the selective mu-opioid receptor agonist fentanyl (Yoshida et al, 1999). As this schedule turned out to be ineffective in antagonizing the effects of EM-2, it was tried to enhance the efficacy of naloxone by reducing its metabolism and, accordingly, increasing its availability in the brain: for that reason, the $10 \mathrm{~min}$ schedule was included. Increasing the dose of naloxone was rejected as strategy, because high doses of this drug produce aspecific effects (Feigenbaum and Howard, 1997).

\section{EXPERIMENTAL PROCEDURES}

\section{Animals}

Male Sprague-Dawley rats (NRC Haruna, Japan) weighing between 200 and $220 \mathrm{~g}$ at the start of the experiment were used. These were housed in a temperature-controlled environment on a 12-h light-dark cycle (light period 0700-1900 h) with free access to food and water.

\section{Surgery}

Rats were anesthetized with sodium pentobarbitone $(50 \mathrm{mg} /$ $\mathrm{kg}$, intraperitoneally (i.p.)). The anesthetized animals were placed in a stereotaxic apparatus, and a guide cannula was implanted just above the left NAc (AP $10.6 \mathrm{~mm}$, ML $1.5 \mathrm{~mm}$, DV $4.0 \mathrm{~mm}$ from interaural line; Paxinos and Watson, 1998) according to previously described procedures (Fusa et al, 2002, 2005; Saigusa et al, 1997, 1999, 2001). To avoid the ventricular system, cannulae directed at the NAc were angled $18^{\circ}$ from the mid-sagittal plane. After completion of surgery, rats were allowed to recover for 7-10 days before experiments were carried out; guide cannulae were kept patent by stainless-steel inserts. Each animal was used only once. The experiments were performed in accordance with institutional, national, and international guidelines for care and welfare of animals. All efforts were made to minimize animal suffering and to reduce the number of animals used.

\section{Dialysis and Neurochemical Measurements}

A commercially available I-shaped removable-type dialysis probe $(2 \mathrm{~mm}$ length cellulose membrane, $0.22 \mathrm{~mm}$ o.d., 50000 mol. wt. 'cutoff', Eicom A-I-8-02 type, Kyoto, Japan) was used. The experiment was started by removing the stylet from the guide cannula and inserting the dialysis probe, of which just the dialysis tubing protruded from the tip. The probe was secured to the guide cannula by a screw. Each rat was then placed in a Plexiglas box $(30 \times 30 \times 35 \mathrm{~cm})$, and inlet and outlet tubes were connected to a swivel located on a counterbalanced beam to minimize discomfort. The probe was perfused at a rate of $2.0 \mu \mathrm{l} / \mathrm{min}$ with modified Ringer solution $(\mathrm{NaCl} 147 \mathrm{mM}, \mathrm{KCl} 4 \mathrm{mM}$, $\mathrm{CaCl}_{2} 1.2 \mathrm{mM}, \mathrm{MgCl}_{2} 1.1 \mathrm{mM} ; \mathrm{pH}$ 7.4) and the outflow connected by Teflon tubing to a high-performance liquid chromatography system (HTEC-500; Eicom, Kyoto, Japan). Dopamine was separated on an Eicompak PP-ODS column (particle size, $2 \mu \mathrm{m}, 4.6 \times 30 \mathrm{~mm}$; Eicom, Kyoto, Japan) maintained at $25^{\circ} \mathrm{C}$, using phosphate buffer $(0.1 \mathrm{M})$ containing decanesulfonic acid (2.0 mM), EDTA $(0.13 \mathrm{mM})$, and $1 \%$ methanol $(\mathrm{pH} 6.0)$ as the mobile phase at a flow rate of $0.5 \mathrm{ml} / \mathrm{min}$. Compounds were quantified by electrochemical detection using a glassy carbon working electrode set at + $400 \mathrm{mV}$ against a silver-silver chloride reference electrode (WE-3G; Eicom, Kyoto, Japan), giving a detection limit for dopamine of about $0.02 \mathrm{pg} / \mathrm{sample}$ at a 2:1 signal-to-noise ratio. The probes had an in vitro recovery of approximately $12 \%$ for dopamine, but the reported concentrations were not adjusted for recovery in vivo because these estimations are inaccurate (Benveniste et al, 1989; Lindefors et al, 1989). Previous experiments in which we have used the same technique and procedure have shown that the dopamine efflux is more or less stabilized $16 \mathrm{~h}$ after probe insertion, 
and that the release seen at that time is largely dependent on neuronal release as more than $70 \%$ of the release is TTX sensitive (Saigusa et al, 2001). Perfusate samples were taken every $5 \mathrm{~min}$ for quantification of dopamine. Drugs were administered either i.p. or intracerebrally through the dialysis probe, at least $20 \mathrm{~h}$ after the probe insertion: baseline levels of dopamine were the mean of the last 12 samples before the drug administration.

\section{Drugs}

Drug used were EM-2 (Peptide Institute Inc., Osaka, Japan), EM-1 (Peptide Institute Inc., Osaka, Japan), TTX (SigmaRBI, St Louis, MO, USA), CTOP (Sigma-RBI, St Louis, MO, USA), naloxone (Sigma-RBI, St Louis, MO, USA), and naloxonazine (naloxonazine dihydrocloride; Sigma-RBI, St Louis, MO, USA). The EM-2, EM-1, and CTOP were dissolved in the modified Ringer solution. The EM-2 and EM-1 were infused via dialysis membrane for $25 \mathrm{~min}$, whereas the CTOP was similarly infused for 50 min (starting $25 \mathrm{~min}$ before EM-2 and EM-1 infusion). The sodium channel blocker TTX was also dissolved in the modified Ringer solution to be used for perfusions and was administered intracerebrally through the dialysis probe. Naloxone was dissolved in saline. Naloxonazine was suspended in $2.5 \%$ Tween- 80 solution and i.p. administered $24 \mathrm{~h}$ before commencing EM-2 infusion. The doses used were based on the outcome of previously reported experiments (EM-2 and EM-1: Sakurada et al, 2001; TTX: Fusa et al, 2002; Saigusa et al, 2001; Takada et al, 1993; Tomiyama et al, 1993, 1995; CTOP: Yoshida et al, 1999; naloxone: Yoshida et al, 1999; naloxonazine: Piepponen and Ahtee, 1995). The reported doses of EM-2 and EM-1 were the amount (nmol) of compounds in $25 \mathrm{~min}$ perfusion liquid $(50 \mu \mathrm{l})$ and the dose of CTOP was the amount of the compound in $50 \mathrm{~min}$ perfusion liquid $(100 \mu \mathrm{l})$.

\section{Histology}

At the end of the experiment, rats were deeply anesthetized with sodium pentobarbitone $(50 \mathrm{mg} / \mathrm{kg}$, i.p.) and perfused transcardially with $10 \%$ formaldehyde solution. The brain was removed, sectioned $(50 \mu \mathrm{m})$, and stained with cresyl violet to permit probe location.

\section{Statistical Analysis}

All values were expressed as a percentage of baseline levels. Comparison of time-course data was performed using twoway ANOVA (analysis of variance) for repeated measures with the factors treatment and time (repeated). Statistical significance was considered to be $P<0.05$.

\section{RESULTS}

\section{Histology}

Placements of the dialysis probes in the NAc are given in Figure 1. Although the tip of the probes were found between the anterior-posterior planes 10.0 and 10.9, they all are projected in a single plane, namely A 10.6 (Figure 1). The length of the probe membrane $(2 \mathrm{~mm})$ prevented a lucid separation between the core and shell region; accordingly,

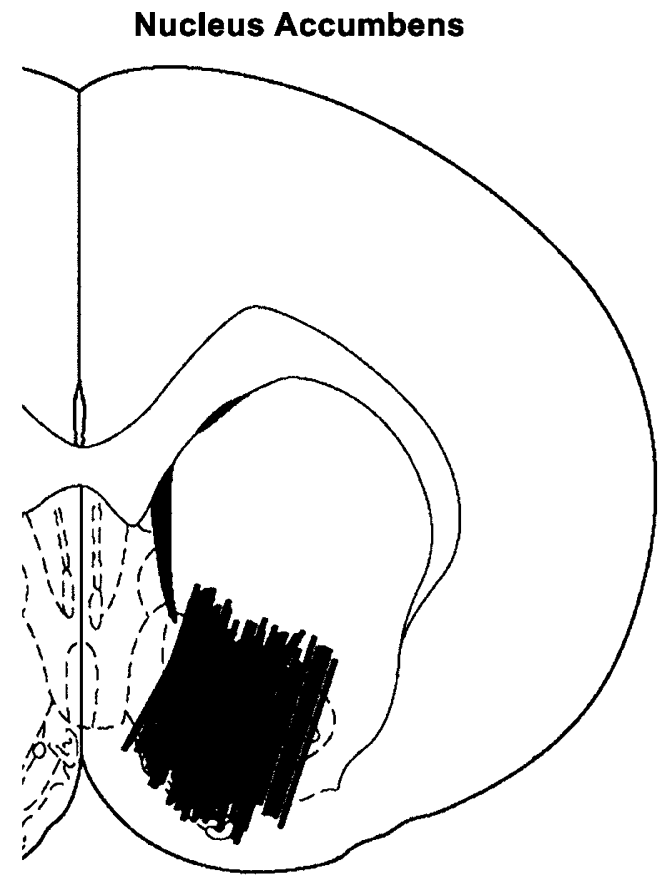

Figure I Schematic illustration showing locations of the probe in the NAc. The diagram is taken from the Atlas of Paxinos and Watson; the number represents anterior distance $(\mathrm{mm})$ from interaural line.

the data are given per NAc rather than per distinct accumbal subregion. The total number of rats used was 189 and the number of rats with misplaced dialysis probes was 30. Only data of rats with correctly placed probes $(n=159)$ were incorporated in the analysis.

\section{Basal Extracellular Dopamine Level in the NAc}

Baseline concentration of dopamine in dialysates from the NAc was $1.0 \pm 0.05 \mathrm{pg} / 5$ min (mean \pm SEM; $n=159$ ).

\section{Effects of EM-2 and EM-1 Perfusion on the Extracellular Dopamine Level in the NAc}

A $25 \mathrm{~min}$ infusion of either EM-2 (Figure 2a; $5 \mathrm{nmol}(n=7)$, $25 \mathrm{nmol}(n=6)$, and $50 \mathrm{nmol}(n=6))$ or EM-1 (Figure $2 \mathrm{~b}$; $5 \mathrm{nmol}(n=6), 25 \mathrm{nmol}(n=6)$, and $50 \mathrm{nmol}(n=6))$ into the NAc produced a dose-dependent increase of the accumbal extracellular dopamine level: these effects lasted for about $10-35 \mathrm{~min}$ (EM-2 - treatment $\mathrm{F}(2,96)=84.92$, $P<0.001$; time $\mathrm{F} \quad(5,96)=4.77, \quad P<0.001$; interaction $\mathrm{F}(10,96)=1.14, P=0.34$; EM- 1 - treatment $\mathrm{F}(2,90)=$ $124.04, P<0.001$; time $\mathrm{F}(5,90)=5.27, P<0.001$; interaction $\mathrm{F}(10,90)=1.91, P=0.05)$

\section{The Neuronal Dependence of the EM-2 and EM-1-Induced Transient Increase of Dopamine Efflux in the NAc}

TTX $(2 \mu \mathrm{M})$ infused for $2 \mathrm{~h}$ via the dialysis probe reduced basal levels of DA by approximately $70 \%$. This TTX infusion almost completely abolished EM-2 $(50 \mathrm{nmol} ; n=6$; Figure 3a; treatment $\mathrm{F}(1,60)=421.58$ : $P<0.001$; time $\mathrm{F}(5,60)=3.89, \quad P<0.01$; interaction $\mathrm{F}(5,60)=2.92$, $P<0.05 ; 10-35 \mathrm{~min})-$ and EM-1 (50 nmol; $n=6$; Figure $3 \mathrm{~b}$ : 

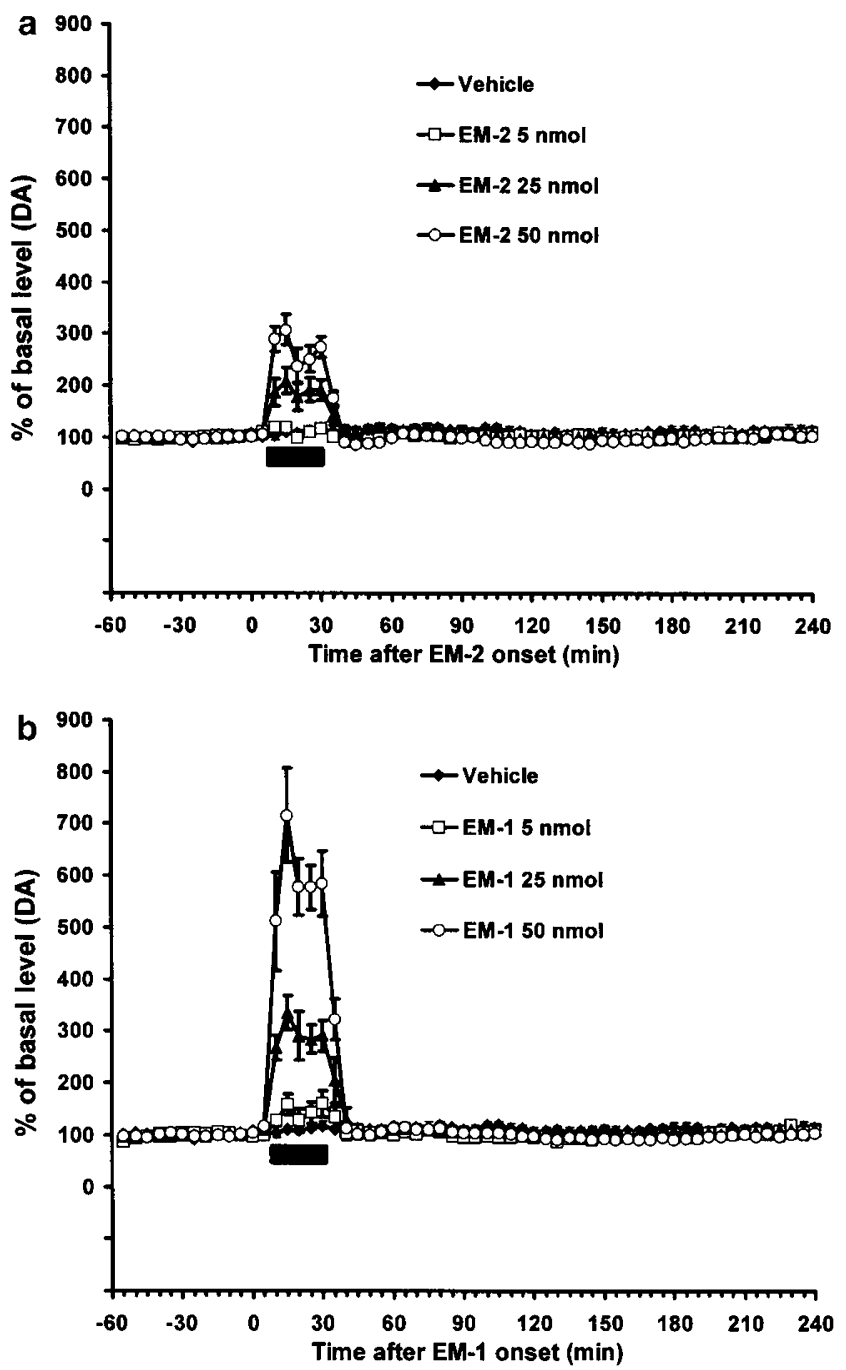

Figure 2 (a) Effects of infusion of vehicle ( $n=6$, filled diamonds), $5 \mathrm{nmol}$ EM-2 ( $n=7$, open squares), $25 \mathrm{nmol} \operatorname{EM}-2$ ( $n=6$, filled triangles), and $50 \mathrm{nmol}$ EM-2 $(n=6$, open circles) into the NAc on basal extracellular levels of dopamine (DA) in the NAc. The data are expressed as the mean of change in 5 min observation periods after the onset of a 25 min infusion of EM-2. Vertical bars indicate SEM. The filled bar above the abscissa indicates the period of infusion of vehicle or EM-2. (b) Effects of infusion of vehicle $(n=6$, filled diamonds), $5 \mathrm{nmol} E M-I \quad(n=6$, open squares), $25 \mathrm{nmol}$ EM-I ( $n=6$, filled triangles), and $50 \mathrm{nmol} \mathrm{EM}-\mathrm{I}(n=6$, open circles) into the NAc on basal extracellular levels of dopamine (DA) in the NAc. The data are expressed as the mean of change in 5 min observation periods after the onset of a 25 min infusion of EM- I. Vertical bars indicate SEM. The filled bar above the abscissa indicates the period of infusion of vehicle or EM-I.

treatment $\mathrm{F}(1,60)=311.50: P<0.01$; time $\mathrm{F}(5,60)=3.78$, $P<0.01$; interaction $\mathrm{F}(5,60)=3.46, P<0.01 ; 10-35 \mathrm{~min})$ induced enhancement of dopamine levels in the NAc. The EM-1 (25 nmol)-induced accumbal dopamine efflux was also completely abolished (data not shown).

\section{Effects of Mu-Opioid Receptor Antagonist on the EM-2- and EM-1-Induced Transient Increase of Dopamine Efflux in the NAc}

Perfusion of the NAc with the mu-opioid receptor antagonist CTOP ( $3 \mathrm{nmol} ; n=6)$ failed to affect the intra-
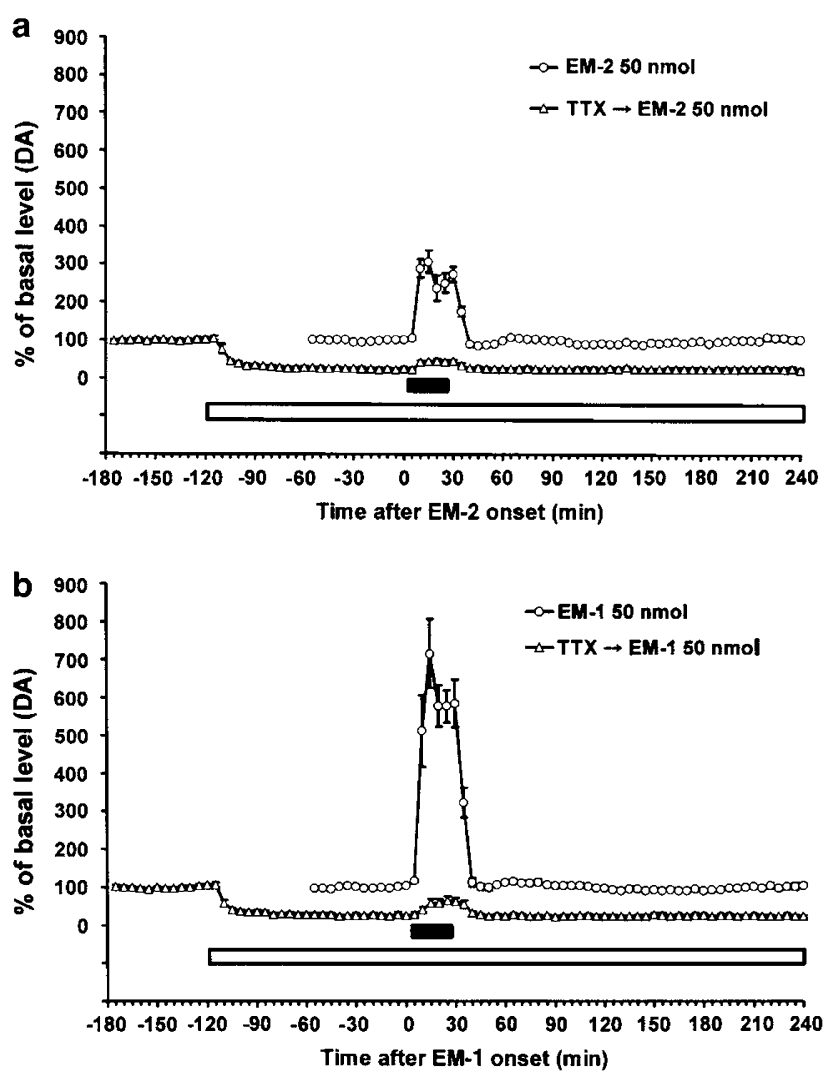

Figure 3 (a) Effects of perfusion of $2 \mu \mathrm{M}$ TTX on a 25 min infusion of $50 \mathrm{nmol}$ EM-2-induced increase in DA (dopamine) levels in the NAc ( $n=6$, open triangles). The data are expressed as the mean of change in 5 min observation periods after the onset of a 25 min infusion of EM-2. Vertical bars indicate SEM. The opened bar above the abscissa indicates the period of TTX perfusion that commenced 120 min before the onset of EM2 infusion. The filled bar indicates the period of infusion of EM-2. (b) Effects of perfusion of $2 \mu \mathrm{M}$ TTX on a $25 \mathrm{~min}$ infusion of $50 \mathrm{nmol} \mathrm{EM}$ - I-induced increase in DA (dopamine) levels in the NAc ( $n=6$, open triangles). The data are expressed as the mean of change in 5 min observation periods after the onset of a $25 \mathrm{~min}$ infusion of EM-I. Vertical bars indicate SEM. The opened bar above the abscissa indicates the period of TTX perfusion that commenced 120 min before the onset of EM-I infusion. The filled bar indicates the period of infusion of EM-I.

accumbal infusion of EM-2 (50 nmol; $n=6)$-induced increase in the extracellular amount of accumbal dopamine (Figure 4a; treatment $\mathrm{F}(1,57)=3.28, \quad P=0.08$; time $\mathrm{F}(5,57)=5.30, \quad P<0.001$; interaction $\mathrm{F}(5,57)=0.04$, $P=1.00 ; 10-35 \mathrm{~min})$. As $25 \mathrm{nmol}$ EM-1 produced effects more less comparable to those produced by $50 \mathrm{nmol} \mathrm{EM}-2$, we initially tested the ability of CTOP to antagonize $25 \mathrm{nmol}$ EM-1. Perfusion of the NAc with the mu-opioid receptor antagonist CTOP ( $3 \mathrm{nmol} ; n=8)$ highly significantly inhibited the effects of EM-1 $(25 \mathrm{nmol} ; n=6)$ on the extracellular amount of accumbal dopamine (Figure 4b; treatment $\mathrm{F}(1,72)=102.79, P<0.001$; time $\mathrm{F}(5,72)=1.05$, $P=0.40$; interaction $\mathrm{F}(5,72)=1.95, P=0.10 ; 10-35 \mathrm{~min})$. CTOP ( 3 nmol; $n=8$ ) was even more effective in inhibiting the effects of a higher dose of EM-1 (50 nmol; Figure 4c; treatment $\mathrm{F}(1,71)=228.57, P<0.001$; time $\mathrm{F}(5,71)=3.33$, $P<0.01$; interaction $\mathrm{F}(5,71)=5.26, P<0.001 ; 10-35 \mathrm{~min})$. The systemic administration of the mul-opioid receptor antagonist naloxonazine $(15 \mathrm{mg} / \mathrm{kg}, 24 \mathrm{~h}$ before the EM-1 perfusion) reduced basal levels of DA till $0.5 \pm 0.08 \mathrm{pg} / 5 \mathrm{~min}$ 

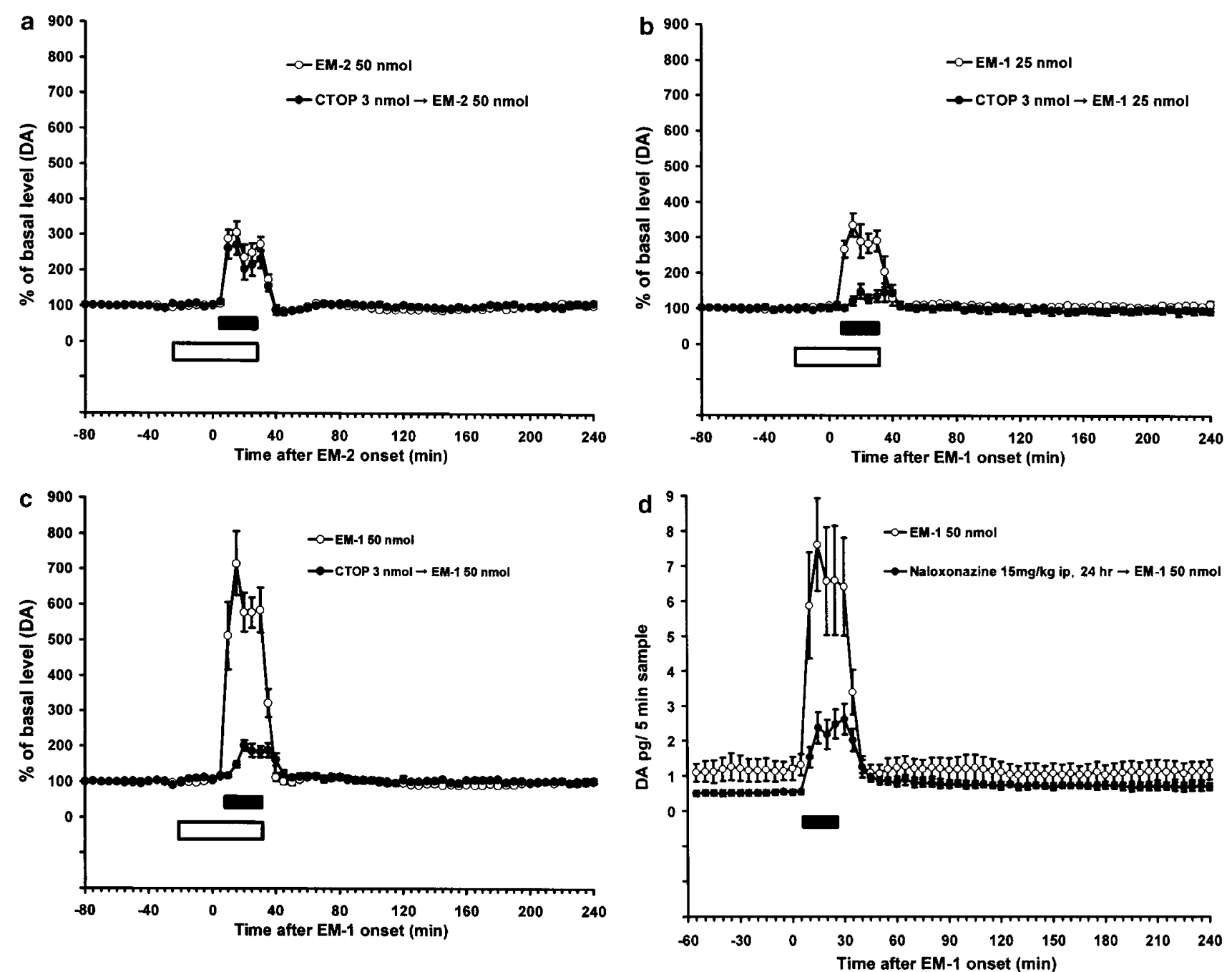

Figure 4 (a) Effects of perfusion of a 50 min infusion of $3 \mathrm{nmol}$ CTOP on a $25 \mathrm{~min}$ infusion of $50 \mathrm{nmol}$ EM-2-induced increase in DA (dopamine) levels in the NAc ( $n=6$, filled circles). The data are expressed as the mean of change in 5 min observation periods after the onset of a 25 min infusion of EM- 2 . Vertical bars indicate SEM. The opened bar above the abscissa indicates the period of CTOP perfusion that commenced 25 min before the onset of EM-2 infusion. The filled bar indicates the period of infusion of EM-2. (b) Effects of perfusion of a 50 min infusion of $3 \mathrm{nmol} C T O P$ on a 25 min infusion of $25 \mathrm{nmol}$ EM-I-induced increase in DA (dopamine) levels in the NAc ( $n=8$, filled circles). The data are expressed as the mean of change in 5 min observation periods after onset of a $25 \mathrm{~min}$ infusion of EM-I. Vertical bars indicate SEM. The opened bar above the abscissa indicates the period of CTOP perfusion that commenced $25 \mathrm{~min}$ before the onset of EM-I infusion. The filled bar indicates the period of infusion of EM-I. (c) Effects of perfusion of a 50 min infusion of $3 \mathrm{nmol}$ CTOP on a $25 \mathrm{~min}$ infusion of $50 \mathrm{nmol}$ EM- I-induced increase in DA (dopamine) levels in the NAc ( $n=8$, filled circles). The data are expressed as the mean of change in 5 min observation periods after the onset of a 25 min infusion of EM-I. Vertical bars indicate SEM. The opened bar above the abscissa indicates the period of CTOP perfusion that commenced 25 min before the onset of EM-I infusion. The filled bar indicates the period of infusion of EM- I. (d) Effects of naloxonazine ( $15 \mathrm{mg} / \mathrm{kg}$, i.p., $24 \mathrm{~h}$ before the onset of EM-I infusion) on a $25 \mathrm{~min}$ infusion of $50 \mathrm{nmol}$ EM- I-induced increase in DA (dopamine) levels in the NAc ( $n=7$, filled circles). Since the basal levels between two groups showed apparent difference, the data are expressed as the mean of absolute amount of DA (pg) in the 5-min sample after the onset of a 25 min infusion of EM-I. Vertical bars indicate SEM. The filled bar above the abscissa indicates the period of infusion of $E M-I$.

$(n=7)$. This naloxonazine pretreatment significantly reduced EM-1 $(50 \mathrm{nmol} ; n=6$; Figure $4 \mathrm{~d}$; treatment $\mathrm{F}$ $(1,66)=51.16, P<0.001$; time $\mathrm{F}(5,66)=1.36, P=0.25$; interaction $\mathrm{F}(5,66)=0.98, P=0.44 ; 10-35 \mathrm{~min})$-induced enhancement of dopamine levels in the NAc.

\section{Effects of Naloxone on the EM-2- and EM-1-Induced} Transient Increase of Dopamine Efflux in the NAc

As shown in Figure 5a, naloxone $(1 \mathrm{mg} / \mathrm{kg}$, i.p., given $20 \mathrm{~min}$ before the intracerebral perfusion), which itself did not significantly affect basal levels of accumbal dopamine (data not shown), failed to affect the EM-2 (50 nmol)-induced enhancement of dopamine level in the NAc $(n=6)$. To enhance the putative efficacy of naloxone, naloxone was also given 10 instead of $20 \mathrm{~min}$ prior to the administration of EM-2; again, naloxone was completely unable to inhibit the effects of EM-2 $(50 \mathrm{nmol})$ on the dopamine level in the NAc (Figure 5b, $n=9$ ). As mentioned above, $25 \mathrm{nmol} \mathrm{EM}-1$ produced effects more or less comparable to those produced by $50 \mathrm{nmol} \mathrm{EM}-2$. For that reason, we initially tested the ability of naloxone $(1 \mathrm{mg} / \mathrm{kg}$, i.p., given $10 \mathrm{~min}$ before the intracerebral perfusion), which itself did not significantly affect basal levels of accumbal dopamine (data not 
shown), to antagonize $25 \mathrm{nmol} \mathrm{EM}-1$. This treatment significantly reduced the EM-1 $(25 \mathrm{nmol})$-induced enhancement of dopamine levels in the NAc, especially during the initial period of $10-30 \mathrm{~min}(n=9$; Figure $5 \mathrm{c}$; treatment $\mathrm{F}(1,78)=42.49, P<0.001$; time $\mathrm{F}(5,78)=2.25, P=0.06$; interaction $F(5,78)=2.27, P=0.06 ; 10-35 \mathrm{~min})$. When naloxone was given $20 \mathrm{~min}$ before the administration of $25 \mathrm{nmol}$ EM-1, it also inhibited its effects EM-1 $(n=9$;
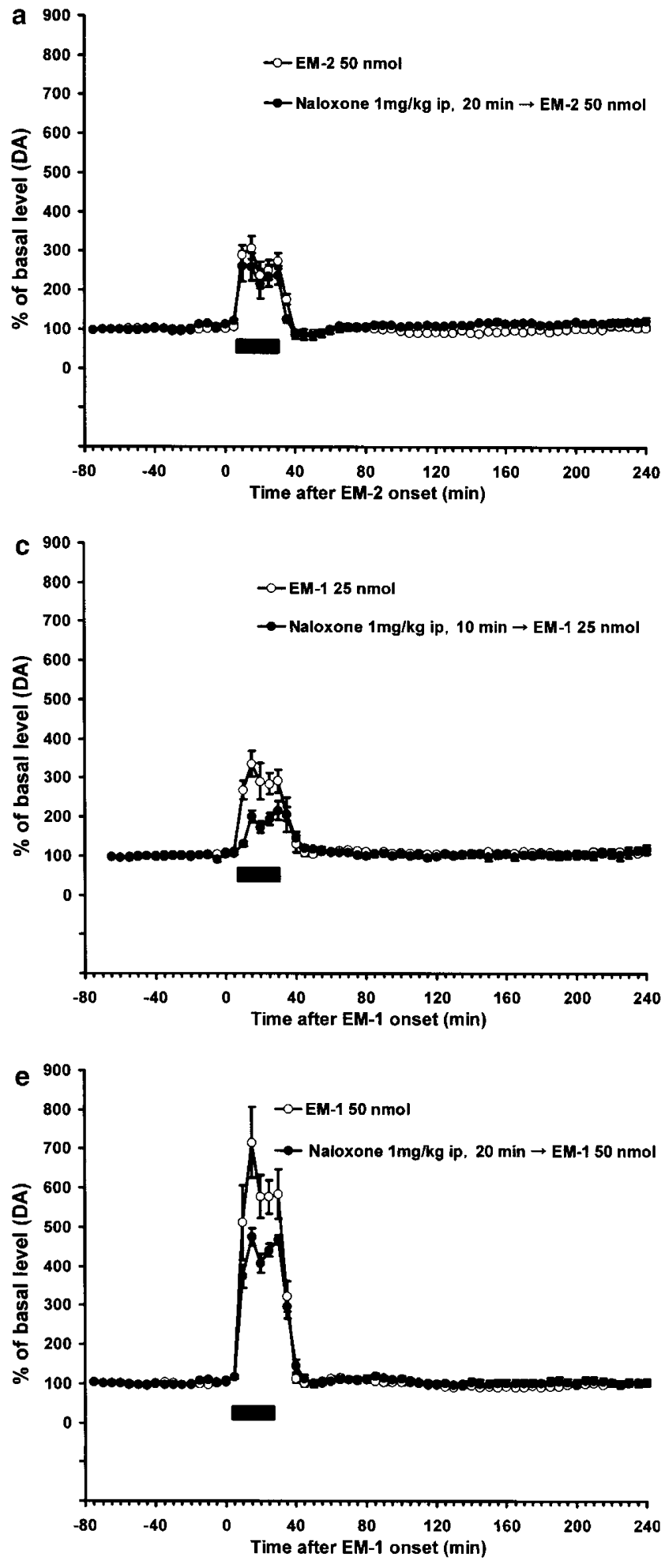

Figure 5d; treatment $\mathrm{F}(1,78)=19.27, P<0.001$; time $\mathrm{F} \quad(5,78)=2.50, \quad P<0.05 ;$ interaction $\mathrm{F} \quad(5,78)=1.59$, $P=0.17 ; 10-35 \mathrm{~min})$. Finally, it was found that naloxone given 20 or $10 \mathrm{~min}$ before the administration of the higher dose of EM-1 $(50 \mathrm{nmol})$ was also effective in inhibiting the effects of EM-1 (20 min interval: Figure $5 e, n=6$; treatment $\mathrm{F}(1,60)=22.33, P<0.001$; time $\mathrm{F}(5,60)=7.35, P<0.001$; interaction $\mathrm{F}(5,60)=0.97, P=0.44 ; 10-35 \mathrm{~min} ; 10 \mathrm{~min}$
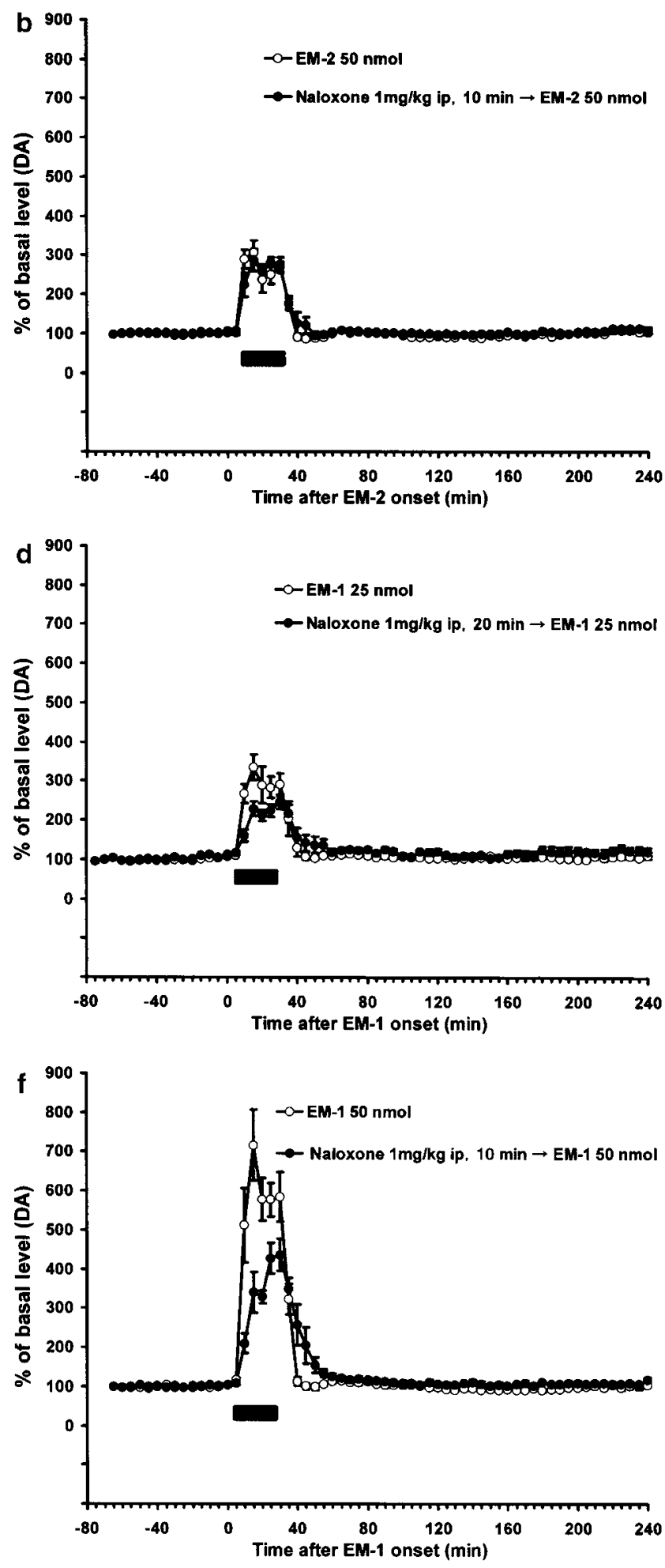
interval: Figure 5f, $n=9$; treatment $\mathrm{F}(1,78)=48.83$, $P<0.001$; time F $(5,78)=5.00, \quad P<0.001$; interaction $\mathrm{F}(5,78)=4.08, P<0.01 ; 10-35 \mathrm{~min})$.

\section{DISCUSSION}

Previously, we have shown that the baseline level of dopamine in the NAc is largely dependent on neuronal activity as more than $70 \%$ of the dopamine release is TTX sensitive (Saigusa et al, 2001). Therefore, it is assumed that the basal dopamine measured in the present study is also primarily due to the neuronal release of dopamine.

The intra-accumbal infusion of EM-2 and EM-1 dose dependently increased the dopamine levels in the dialysate from the NAc of rats. A quantitative difference between the effects of EM-2 and EM-1 on the induction of increase in accumbal dopamine efflux was observed. Thus, the ability of EM-2 to enhance the accumbal extracellular dopamine levels was far smaller than that of EM-1, when a broad range of doses $(5,25$, and $50 \mathrm{nmol})$ was tested. The maximal effects caused by the infusion of the highest dose $(50 \mathrm{nmol})$ of EM-2 and EM-1 were nearly fully suppressed by the intraaccumbal infusion of TTX $(2 \mu \mathrm{M})$, indicating that, under the present experimental conditions, the EM-2- and EM-1induced increases of accumbal dopamine levels were fully dependent on neuronal firing activity. As discussed below, the effects of EM-1 were mediated via mechanisms that fully differ from those mediating the effects of EM-2. For that reason, the differences in efficacy between EM-1 and EM-2 cannot be simply ascribed to a difference in affinity and/or intrinsic activity, but to a difference in mechanisms.

In order to investigate the role of opioid receptors in the endomorphins' action on the mesolimbic dopaminergic system, the mu-opioid receptor antagonist CTOP was directly infused into NAc to inhibit the effects of EM-2 or EM-1 on the extracellular amount of dopamine. Initially, it was attempted to counteract a drug-induced increase of extracellular dopamine that did not differ between EM-2 and EM-1; for that purpose, a dose of $50 \mathrm{nmol} \mathrm{EM-2}$ and a dose of $25 \mathrm{nmol} \mathrm{EM-1}$ were chosen. In contrast to the EM-2induced effects that were not at all inhibited by CTOP, the effects of EM-1 were nicely inhibited by this compound ( $3 \mathrm{nmol}$ ), indicating that the effects of EM-1, but not EM-2, were mediated via mu-opioid receptors. The finding that
$3 \mathrm{nmol}$ CTOP also nearly completely inhibited the effects induced by a higher dose of EM-1 $(50 \mathrm{nmol})$ confirms the above-mentioned conclusion that the EM-1-induced effects were specific of mu-opioid receptors. The additional finding that the systemic administration of the putative mul-opioid receptor antagonist naloxonazine also inhibited the EM-1induced accumbal dopamine efflux not only underlines the involvement of mu-opioid receptors but also suggests that the involved receptors belong to the mul-opioid receptor subtype. Apart from this conclusion, the data suggest that the effects induced by EM-2 were not mediated via muopioid receptors. The experiments in which the ability of the aspecific opioid receptor antagonist naloxone was tested not only confirmed that the effects of EM-1 were mediated via the naloxone-sensitive opioid receptors but also revealed that the effects induced by EM-2 were not at all mediated via opioid receptors that are blocked by naloxone. For, neither naloxone given $20 \mathrm{~min}$ before EM-2 nor naloxone given $10 \mathrm{~min}$ before this drug was able to antagonize the effects of EM-2. This lack of inhibition cannot be ascribed to an inability of the chosen doses or treatment to reduce effects mediated via stimulation of opioid receptors, because these treatments were highly effective in attenuating the effects of EM-1 (present study); as mentioned in the Introduction, this treatment has been found to be effective in other studies as well. In other words, the present study provides the original evidence that EM-1, like fentanyl, enhances the dopamine efflux in the NAc via direct stimulation of mu-opioid receptors in this nucleus. As a final remark in this context, it has been recently reported that CTOP is less mu-opioid receptor specific than it has originally been stated: for, it can also bind to somatostatin receptors (Chieng et al, 1996); CTAP would be a better choice. However, the finding that both CTOP and naloxonazine inhibited the effects of EM-1 clearly shows that the involved receptors belong to the mu-opioid receptors.

The finding that EM-2-induced effects are not always mediated via opioid receptors fits in with the earlier reported fact that the inhibitory action of EM-2 upon the tachykinergic contractions of guinea-pig-isolated bronchus is insensitive of specific antagonists of the mu-, kappa-, and delta-opioid receptors, as well as insensitive of aspecific opioid receptor antagonists such as naloxone (Fischer and Undem, 1999). The present study clearly shows that this

Figure 5 (a) Effects of naloxone (I mg/kg, i.p., 20 min before the onset of EM-2 infusion) on a 25 min-infusion of $50 \mathrm{nmol}$ EM-2-induced increase in DA (dopamine) levels in the NAc ( $n=6$, filled circles). The data are expressed as the mean of change in 5 min observation periods after the onset of a 25 min infusion of EM-2. Vertical bars indicate SEM. The filled bar above the abscissa indicates the period of infusion of EM-2. (b) Effects of naloxone (I mg/kg, i.p., 10 min before the onset of EM-2 infusion) on a 25 min infusion of 50 nmol EM-2-induced increase in DA (dopamine) levels in the NAc ( $n=9$, filled circles). The data are expressed as the mean of change in 5 min observation periods after the onset of a 25 min infusion of EM-2. Vertical bars indicate SEM. The filled bar above the abscissa indicates the period of infusion of EM-2. (c) Effects of naloxone (I mg/kg, i.p., $10 \mathrm{~min}$ before the onset of EM-I infusion) on a $25 \mathrm{~min}$ infusion of $25 \mathrm{nmol}$ EM- I-induced increase in DA (dopamine) levels in the NAc ( $n=9$, filled circles). The data are expressed as the mean of change in 5 min observation periods after the onset of a 25 min infusion of EM-I. Vertical bars indicate SEM. The filled bar above the abscissa indicates the period of infusion of EM-I. (d) Effects of naloxone (I mg/kg, i.p., 20 min before the onset of EM- I infusion) on a 25 min infusion of $25 \mathrm{nmol}$ EM-I-induced increase in DA (dopamine) levels in the NAc ( $n=9$, filled circles). The data are expressed as the mean of change in 5 min observation periods after the onset of a 25 min infusion of EM-I. Vertical bars indicate SEM. The filled bar above the abscissa indicates the period of infusion of EM-I. (e) Effects of naloxone (I mg/kg, i.p., 20 min before the onset of EM-I infusion) on a 25 min infusion of 50 nmol EM-I-induced increase in DA (dopamine) levels in the NAc ( $n=6$, filled circles). The data are expressed as the mean of change in 5 min observation periods after the onset of a 25 min infusion of EM- I. Vertical bars indicate SEM. The filled bar above the abscissa indicates the period of infusion of EM- I. (f) Effects of naloxone (I mg/kg, i.p., $10 \mathrm{~min}$ before the onset of EM-2 infusion) on a $25 \mathrm{~min}$ infusion of $50 \mathrm{nmol}$ EM- I-induced increase in DA (dopamine) levels in the NAc ( $n=9$, filled circles). The data are expressed as the mean of change in 5 min observation periods after the onset of a 25 min infusion of EM-I. Vertical bars indicate SEM. The filled bar above the abscissa indicates the period of infusion of EM-I. 
also holds for effects of EM-2 in the central nervous system. Indeed, endomorphins have been found to bind to nonopioid binding sites in tissues lacking mu receptors, such as rat cerebellum or brain of homozygous transgenic MOR -I- mice (review: Wollemann and Benyhe, 2004). Remarkably, there are more agents that are known to act as opioid receptor agonists, but nevertheless produce effects that are not at all mediated via these receptors. For instance, DAMGO, a mu-opioid receptor agonist, reduces NMDA currents via a nonmu-opioid receptor mechanism (Martin et al, 1997), and dynorphin A, a kappa receptor agonist, induces a naloxone-insensitive reduction in dopamine uptake (Das et al, 1994). The most interesting finding in this respect is the discovery that the so-called delta-opioid receptor agonist (-)-TAN-67 can produce effects that are fully independent of interaction with opioid receptors: it can produce an increase of the extracellular dopamine level in the NAc via the generation of a burst of free radicals that in turn trigger a release of glutamate, which ultimately via activation of NMDA receptors enhances the release of dopamine from dopaminergic terminals in the NAc (Fusa et al, 2005). To what extent the effects of EM-2 described in the present study are also due to such a mechanism of action remains to be investigated in future studies. Taken together, the present study reveals that the effects of EM-2 are not mediated via opioid receptors, despite the fact that EM-2 is known to be able to stimulate directly mu-opioid receptors (see Introduction) and, indirectly, the kappaopioid receptors (Tseng et al, 2000; Ohsawa et al, 2001).

In summary, the present study reveals that the intraaccumbal infusion of EM-2 and EM-1 increases dopamine efflux in the NAc by mechanisms that fully differ. Although the effects of both EM-2 and EM-1 are dependent on neuronal activity, the effects of EM-2 could not be blocked by an otherwise effective dose of the selective mu-opioid receptor antagonist CTOP or the aspecific opioid receptor antagonist naloxone in contrast to the effects of EM-1 that were very effectively counteracted by CTOP, naloxonazine, and naloxone. It is concluded that the effects of EM-2 are not mediated via naloxone-sensitive opioid receptors in contrast to the effects of EM-1 that are mediated via mu1opioid receptors in the NAc.

\section{ACKNOWLEDGEMENTS}

This study was supported by Research Grants from the Sato Fund (TS, NK) and Dental Research Centre (NK), Nihon University School of Dentistry; Nihon University Multidisciplinary Research Grant for 2005/2006 (TS, NK, ARC); a grant for promotion of multidisciplinary research project (NK, ARC) and a grant-in-aid for scientific research (\# 14370609 to NK and \# 16591897 to TS) from the Ministry of Education, Culture, Sports, Science, and Technology, Japan; and The Promotion and Mutual Aid Corporation for Private School of Japan (SW, IT, YA, NK).

\section{REFERENCES}

Benveniste H, Hansen AJ, Ottosen NS (1989). Determination of brain interstitial concentrations by microdialysis. J Neurochem 52: 1741-1750.
Champion HC, Zadina JE, Kastin AJ, Hackler L, Ge LJ, Kadowitz PJ (1997). Endomorphin 1 and 2, endogenous ligands for the muopioid receptor, decrease cardiac output, and total peripheral resistance in the rat. Peptides 18: 1393-1397.

Chapman V, Diaz A, Dickenson AH (1997). Distinct inhibitory effects of spinal endomorphin-1 and endomorphin-2 on evoked dorsal horn neuronal responses in the rat. $\mathrm{Br} J$ Pharmacol 122: 1537-1539.

Chieng B, Connor M, Christie MJ (1996). The mu-opioid receptor antagonist D-Phe-Cys-Tyr-D-Trp-Orn-Thr-Pen-Thr- $\mathrm{NH}_{2}$ (CTOP) [but not D-Phe-Cys-Tyr-D-Trp-Arg-Thr-Pen-Thr- $\mathrm{NH}_{2}$ (CTAP)] produces a nonopioid receptor-mediated increase in $\mathrm{K}^{+}$ conductance of rat locus ceruleus neurons. Mol Pharmacol 50: 650-655.

Czapla MA, Champion HC, Zadina JE, Kastin AJ, Hackler L, Ge LJ et al (1998). Endomorphin 1 and 2, endogenous mu-opioid agonists, decrease systemic arterial pressure in the rat. Life Sci 62: PL175-179.

Das D, Rogers J, Michael-Titus AT (1994). Comparative study of the effects of mu, delta and kappa opioid agonists on ${ }^{3} \mathrm{H}$ dopamine uptake in rat striatum and nucleus accumbens. Neuropharmacology 33: 221-226.

Feigenbaum JJ, Howard SG (1997). Effects of naloxone on amphetamine induced striatal dopamine release in vivo: a microdialysis study. Life Sci 60: 1659-1668.

Fischer A, Undem BJ (1999). Naloxone blocks endomorphin-1 but not endomorphin-2 induced inhibition of tachykinergic contractions of guinea-pig isolated bronchus. $\mathrm{Br} \mathrm{J}$ Pharmacol 127: 605-608.

Fusa K, Saigusa T, Koshikawa N, Cools AR (2002). Tyrosineinduced release of dopamine is under inhibitory control of presynaptic dopamine D2 and, probably, D3 receptors in the dorsal striatum, but not in the nucleus accumbens. Eur $J$ Pharmacol 448: 143-150.

Fusa K, Takahashi I, Watanabe S, Aono Y, Ikeda H, Saigusa T et al (2005). The non-peptidic delta opioid receptor agonist TAN-67 enhances dopamine efflux in the nucleus accumbens of freely moving rats via a mechanism that involves both glutamate and free radicals. Neuroscience 130: 745-755.

Goldberg IE, Rossi GC, Letchworth SR, Mathis JP, Ryan-Moro J, Leventhal L et al (1998). Pharmacological characterization of endomorphin-1 and endomorphin-2 in mouse brain. J Pharmacol Exp Ther 286: 1007-1013.

Hackler L, Zadina JE, Ge L-J, Kastin AJ (1997). Isolation of relatively large amounts of endomorphin-1 and endomorphin-2 from human brain cortex. Peptides 18: 1635-1639.

Lindefors N, Amberg G, Ungerstedt U (1989). Intracerebral microdialysis: I. Experimental studies of diffusion kinetics. J Pharmacol Methods 22: 141-156.

Martin G, Nie Z, Siggins GR (1997). Mu-opioid receptors modulate NMDA receptor-mediated responses in nucleus accumbens neurons. J Neurosci 17: 11-22.

Martin-Schild S, Gerall AA, Kastin AJ, Zadina JE (1999). Differential distribution of endomorphin 1- and endomorphin 2-like immunoreactivities in the CNS of the rodent. J Comp Neurol 405: 450-471.

Mehta A, Bot G, Reisine T, Chesselet MF (2001). Endomorphin-1: induction of motor behavior and lack of receptor desensitization. J Neurosci 21: 4436-4442.

Murai T, Koshikawa N, Kanayama T, Takada K, Tomiyama K, Kobayashi M (1994). Opposite effects of midazolam and betacarboline-3-carboxylate ethyl ester on the release of dopamine from rat nucleus accumbens measured by in vivo microdialysis. Eur J Pharmacol 261: 65-71.

Ohsawa M, Mizoguchi H, Narita M, Nagase H, Kampine JP, Tseng LF (2001). Differential antinociception induced by spinally administered endomorphin-1 and endomorphin-2 in the mouse. J Pharmacol Exp Ther 298: 592-597. 
Pasternak GW, Wood PJ (1986). Multiple mu opiate receptors. Life Sci 38: $1889-1898$.

Paxinos G, Watson C (1998). The Rat Brain in Sterotaxic Coordinates, 4th edn. Academic Press: New York.

Piepponen TP, Ahtee L (1995). Effects of selective opioid receptor antagonists on morphine-induced changes in striatal and limbic dopamine metabolism. Pharmacol Toxicol 77: 204-208.

Saigusa T, Fusa K, Okutsu H, Koshikawa N (2001). Monitoring of extracellular dopamine levels in the dorsal striatum and the nucleus accumbens with 5-minute on-line microdialysis in freely moving rats. J Oral Sci 43: 129-134.

Saigusa T, Takada K, Baker SC, Kumar R, Stephenson JD (1997). Dopamine efflux in the rat nucleus accumbens evoked by dopamine receptor stimulation in the entorhinal cortex is modulated by oestradiol and progesterone. Synapse 25: $37-43$.

Saigusa T, Tuinstra T, Koshikawa N, Cools AR (1999). High and low responders to novelty: effects of a catecholamine synthesis inhibitor on novelty-induced changes in behavior and release of accumbal dopamine. Neuroscience 88: 1153-1163.

Sakurada S, Hayashi T, Yuhki M, Fujimura T, Murayama K, Yonezawa A et al (2002). Differential antagonism of endomorphin-1 and endomorphin-2 supraspinal antinociception by naloxonazine and 3-methylnaltrexone. Peptides 23: 895-901.

Sakurada S, Hayashi T, Yuhki M, Fujimura T, Murayama K, Yonezawa A et al (2000). Differential antagonism of endomorphin-1 and endomorphin-2 spinal antinociception by naloxonazine and 3-methoxynaltrexone. Brain Res 881: 1-8.

Sakurada S, Hayashi T, Yuhki M, Orito T, Zadina JE, Kastin AJ et al (2001). Differential antinociceptive effects induced by intrathecally administered endomorphin-1 and endomorphin-2 in the mouse. Eur J Pharmacol 427: 203-210.

Sakurada S, Zadina JE, Kastin AJ, Katsuyama S, Fujimura T, Murayama K et al (1999). Differential involvement of mu-opioid receptor subtypes in endomorphin-1- and -2-induced antinociception. Eur J Pharmacol 372: 25-30.
EM-2- and EM-I-induced accumbal dopamine efflux

$\mathrm{H}$ Okutsu et al

Schreff M, Schulz S, Wiborny D, Hollt V (1998). Immunofluorescent identification of endomorphin-2-containing nerve fibers and terminals in the rat brain and spinal cord. Neuroreport 9: 1031-1034.

Stone LS, Fairbanks CA, Laughlin TM, Nguyen HO, Bushy TM, Wessendorf MW et al (1997). Spinal analgesic actions of the new endogenous opioid peptides endomorphin-1 and -2. Neuroreport 8: $3131-3135$

Takada K, Murai T, Kanayama T, Koshikawa N (1993). Effects of midazolam and flunitrazepam on the release of dopamine from rat striatum measured by in vivo microdialysis. $\mathrm{Br} J$ Anaesth 70: 181-185.

Tomiyama K, Koshikawa N, Funada K, Oka K, Kobayashi M (1995). In vivo microdialysis evidence for transient dopamine release by benzazepines in rat striatum. J Neurochem 65: 2790-2795.

Tomiyama K, Noguchi M, Koshikawa N, Kobayashi M (1993). YM09151-2 but not 1-sulpiride induces transient dopamine release in rat striatum via a tetrodotoxin-insensitive mechanism. J Neurochem 60: 1690-1695.

Tseng LF, Narita M, Suganuma C, Mizoguchi H, Ohsawa M, Nagase $\mathrm{H}$ et al (2000). Differential antinociceptive effects of endomorphin-1 and endomorphin-2 in the mouse. J Pharmacol Exp Ther 292: 576-583.

Wang XM, Zhang KM, Long LO, Flores CA, Mokha SS (2000). Endomorphin-1 and endomorphin-2 modulate responses of trigeminal neurons evoked by $N$-methyl-D-aspartic acid and somatosensory stimuli. J Neurophysiol 83: 3570-3574.

Wollemann M, Benyhe S (2004). Non-opioid actions of opioid peptides. Life Sci 75: 257-270.

Yoshida Y, Koide S, Hirose N, Takada K, Tomiyama K, Koshikawa $\mathrm{N}$ et al (1999). Fentanyl increases dopamine release in rat nucleus accumbens: involvement of mesolimbic mu- and delta2-opioid receptors. Neuroscience 92: 1357-1365.

Zadina JE, Hackler L, Ge L-J, Kastin AJ (1997). A potent and selective endogenous agonist for the mu-opiate receptor. Nature 386: $499-502$. 